Document downloaded from:

http://hdl.handle.net/10251/97787

This paper must be cited as:

Juan Borras, MDS.; Doménech Antich, EM.; Escriche Roberto, MI. (2016). Mixture-riskassessment of pesticide residues in retail polyfloral honey. Food Control. 67:127-134. doi:10.1016/j.foodcont.2016.02.051

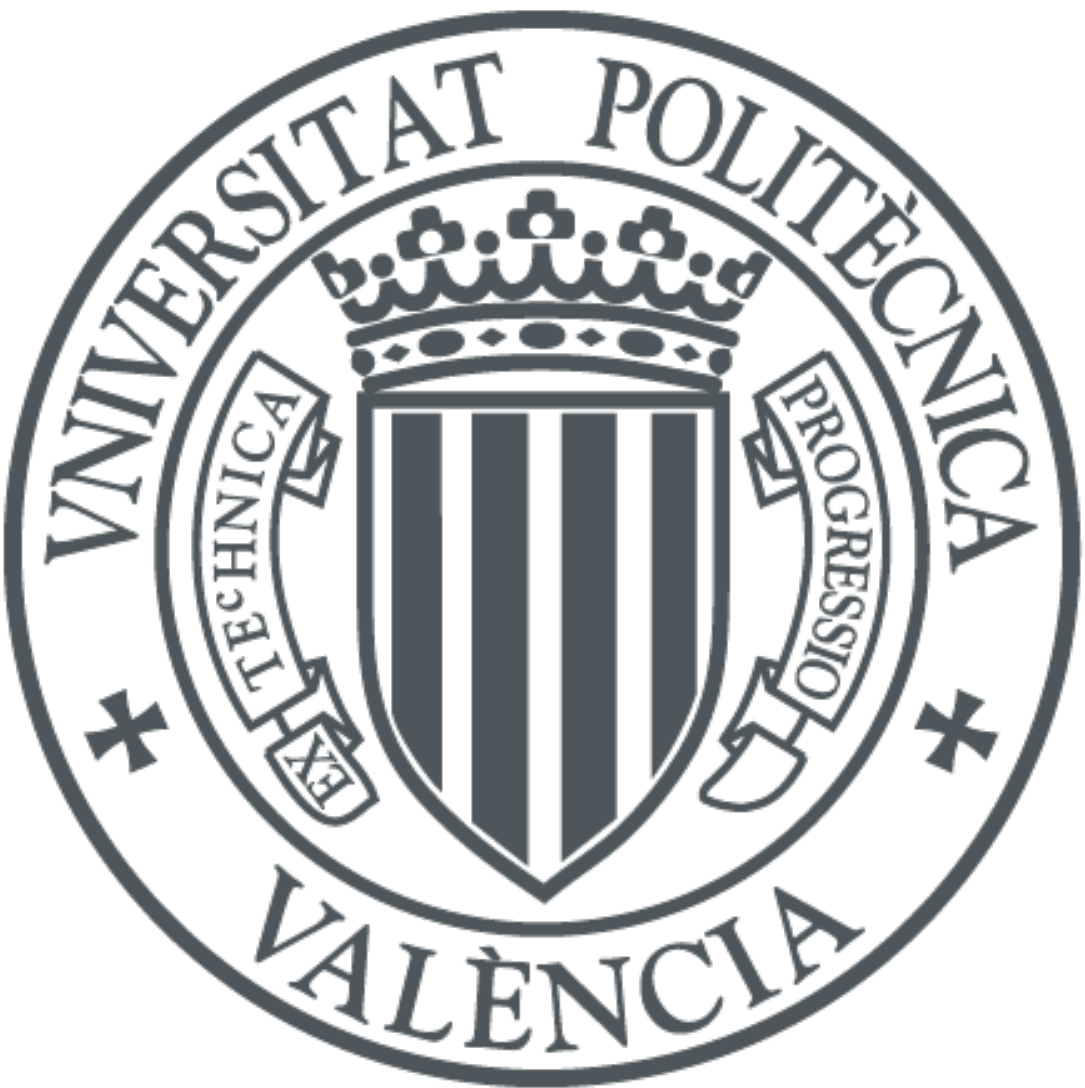

The final publication is available at

https://doi.org/10.1016/j.foodcont.2016.02.051

Copyright Elsevier

Additional Information 


\title{
Mixture-risk-assessment of pesticide residues in retail polyfloral honey
}

\author{
Marisol Juan-Borrás, Eva Domenech, Isabel Escriche* \\ Institute of Food Engineering for Development (IUIAD), Food Technology Department \\ (DTA), Universitat Politecnica de Valencia, P.O. Box 46022, Valencia, Spain.
}

*iescrich@tal.upv.es

\begin{abstract}
The presence of even tiny quantities of pesticide residues in honey, a traditional healthy product, is a matter of concern for producers, packers and consumers. This paper aims to quantify pesticides in retail brands of polyfloral honey, and to calculate the mixture risk assessment of honey for consumers according to the results obtained from the analyzed samples. A LC-MS/MS multi-residue method was developed and validated for 13 compounds: 11 pesticides (chlorfenvinphos, coumaphos, tau-fluvalinate, amitraz, which are very common in veterinary treatments, and imidacloprid, acetamiprid, simazine, cyproconazole, tebuconazole, chlorpiryphos-methyl, chlorpiryphos, widely used in agricultural practices), and 2 metabolites of amitraz (2,4-DMA and 2,4-DMF). Results showed that the samples contained pesticide residues at different concentrations; however, the MRL in honey for each of the 11 pesticides was never exceeded. The most common were amitraz (from 1 to $50 \mu \mathrm{g} / \mathrm{kg}$ ) present in $100 \%$ of the samples, and coumaphos (up to $14 \mu \mathrm{g} / \mathrm{kg}$ ) in 63\%. The hazard index (HI) for adults was less than 0.002 in all cases, a long way from 1 , the value established as the limit of acceptability. Therefore, commercial honey does not represent any significant risk to health. However, considering that residue levels should be present "as low as reasonably achievable" it is deemed necessary to make an effort to reduce their presence by appropriate agricultural and, above all, beekeeping practices due to acaridae treatments.
\end{abstract}

Keywords: Honey; pesticides; Mixture-risk-assessment; MRL; hazard index 


\section{Introduction}

Honey is a highly valued natural product due to its nutritional properties and appreciated therapeutic applications. However, recently, food alerts caused by the detection of antibiotics, pesticides or heavy metals in honey have jeopardized its healthy image (JuanBorrás et al., 2015). Pesticide residues in honey come from environmental pollution and veterinary practices (Totti et al., 2006; Calatayud-Vernich et al., 2016).

Honeybees come into contact with pesticides because veterinary practices expose them to pesticides such as acaricides required to control bee parasites like Varroa destructor and Varroa jacobsonie (Li et al., 2015) and fungicides to control Ascosphera apis, as well as other chemical agents such as antibiotics, and sulphonamides used to control bacterial diseases like European foulbrood (Streptococcus pluton) or American foulbrood (Bacillus larvae).

On the other hand, another source of contamination is a wide range of pathways such as contaminated water, pollen and nectar from treated plants and crops, or even by direct contact during flight (García-Chao et al., 2010; Rodriguez-López, et al., 2014). Currently in Europe, the majority of insecticides used in agricultural practices are organophosphates, carbamates and neonicotinoids, although in some countries the use of a number of them is forbidden. These compounds affect the central nervous system of beneficial insects such as honeybees, by inhibiting the activity of the enzyme acetylcholinesterase (Blasco et al., 2011); Tanner \& Czerwenka, 2011).

Combinations of sub-lethal doses of modern pesticides, of any origin, often produce additive or even synergistic effects on the mortality and behaviour of animals, which contributes to Colony Collapse Disorder (CCD) (Van Engelsdorp et al., 2009).These pesticides not only affect the insects, but also contaminate bee products like honey. The determination of contaminants and residues in honey and other bee products has become a growing concern in recent years, especially as these compounds may diminish the beneficial properties of honey and, if present in significant amounts, may pose a serious threat to human health (Kujawski \& Namiesnik, 2011).

In order to protect human health, chemical hazards must be controlled to stop pesticides reaching the food chain (Blasco et al., 2011; Barganska et al., 2013). With this aim in mind, Regulation (EC) 396/2005 and Regulation (EC) 37/2010 established MRLs for residues of certain specific pharmacologically active substances in foodstuffs of animal 
origin (for instance, coumaphos and amitraz in honey). This lowering of the limits of detection in a matrix as complex as honey is only possible thanks to modern analytical techniques (GC-MS-MS and LC-MS/MS) and adequate extraction and cleaning of analytes using QuEChERs (Blasco et al., 2011; Barganska et al., 2013; Hou et al., 2013). Presently, dietary assessment of the exposure to pesticide residues and other chemical agents is usually evaluated on a chemical-by-chemical basis. However, consumers are exposed to more than one pesticide through diet, because food may contain more than one residue or people consume combinations of foods containing different pesticides. If these compounds have the same toxicological mechanism of action, the usual method of assessing the dietary risk of exposure to pesticides individually may result in an underestimation of the health risk (Gallagher et al., 2015; Judge et al., 2016). For instance, some organophosphorus (OPs), carbamate (CBs), and pyrethrin and pyrethroid (PPs) pesticides, causing a common neurotoxic effect, have been identified by United States Environmental Protection Agency (USEPA) as members of the same cumulative assessment group (USEPA, 2006; USEPA, 2007a; USEPA, 2011). Therefore, to address the risk of exposure to different compounds, the individual approach may not be sufficiently protective (Boobis et al., 2008; Kortenkamp, et al., 2009). However, the existence of a mixture of chemicals is not always an indication of a risk to human or environmental health, but indicates the need for more accurate estimations of risk by considering all of the chemicals present. Hence, in relation to a new metric known as Mixture Risk Assessment (MRA), introduced to assess the cumulative risk to human health, different guidelines have been published: Environmental Protection Agency of the USA (USEPA 2002), the UK Committee on Toxicity of Chemicals in Food, Consumer Products and the Environment (COT, 2002), the Norwegian Scientific Committee for Food Safety (VKM 2008), the German CVUA (CVUA, 2007), etc. General support for the risk assessment of combined exposures and associated terminology was defined at OECD-WHO-ILSI-HESI Workshop in 2011 (OECD 2011). Furthermore, EFSA is harmonising the assessment of chemical mixtures terminology and methodologies and has already developed some approaches in this field. Recent examples include the risk assessment of mixtures of pesticides for humans and bees, and mixtures of contaminants for humans (EFSA, 2013).

In this context, different works have been reported recently about the implementation of this metric for heavy metals in industrial areas (Zheng et al., 2007) and in pesticides in fresh vegetables and fruit (Boobis, et al., 2008; Evans et al., 2015 and Yu et al., 2016, Quijano 
et al., 2016). However, this is the first attempt to apply this approach to retail honey. Therefore, the objective of this paper was to quantify the presence of different pesticides (usually found in the routine control analyses of honey samples) in polyfloral labeled brands, and to estimate the mixture risk assessment of the honey for consumers (due to exposure to pesticides) based on the results obtained from the analyzed samples. As a first step, the analytical procedure was validated in order to guarantee the quality of the results obtained.

\section{Material and Methods}

\subsection{Honey samples}

This study was carried out with supermarket own-brands and well-known brand honey, which represent almost all of the retail sales in the Spanish market. A total of 22 honey samples, labelled as polyfloral were purchased across Spain from different retail outlets. Samples were purchased with as recent a packing date as possible, based on the label information, and were kept frozen until analysis to minimize losses of target compounds. A mixture of 5 polyfloral honeys without the compounds analyzed in this study was selected as a "blank honey" in order to perform the validation procedure of the methodology.These samples were provided directly by Spanish beekeepers.

In all the samples the percentage of pollen of the different botanical species was evaluated in order to estimate their geographical origin. There was only one sample for which it was not possible to perform this characterization due to the insufficient presence of pollen.

\subsection{Pesticide analysis}

The QuECheRS technique was used for the extraction of pesticides and liquid chromatography-mass spectrometry (LC-MS/MS) for their analysis (Kasiotis et al., 2014; Calatayud-Vernich, el al.,2016).

\subsubsection{Standards and reagents}

Table 1 shows the 11 pesticides analysed in the present work. All of them [including the two metabolites of amitraz: 2,4-DMA (2,4-dimethylaniline) and 2,4-DMF (N-2,4dimethylphenyl formamide)], were purchased from Sigma-Aldrich, (Steinheim, Alemania), with a purity of $\geq 99 \%$.

Individual stock standard solutions $(200 \mu \mathrm{g} / \mathrm{mL})$ were prepared in methanol $(\mathrm{MeOH})$ or acetonitrile (MeCN), depending on the solubility of each pesticide. Specifically, amitraz stock standard was prepared by dissolving in acetonitrile because amitraz is more stable 
in this solvent (Corta et al., 1999, Xu, et al., 2009). All the solutions were stored at $-20^{\circ}$ C in order to improve their stability (Tokmana, et. al, 2009). In this way, they were stable for at least 1 year. From them, a stock standard mixture of 13 pesticides was made weekly in $\mathrm{MeCN}$ (each analyte at a concentration of $40 \mu \mathrm{g} / \mathrm{mL}$ ) and stored in amber glass vials at $-20^{\circ} \mathrm{C}$. The spiking solutions $(10 \mu \mathrm{g} / \mathrm{mL}$ and $1 \mu \mathrm{g} / \mathrm{mL})$ were prepared in ultrapure water from the stock standard mixture solution and stored in amber glass vials at $-4^{\circ} \mathrm{C}$.

The MeOH used for the mobile phase was MS-Grade (Scharlab, Barcelona). The $\mathrm{MeOH}$ and MeCN used for sample extraction (Quechers methodology) and for the standards preparation was HPLC grade and was obtained from Prolabo (VWR, France). The formic acid (purity 99\%) for LC-MS analysis, analytical grade sodium chloride $(\mathrm{NaCl})$, anhydrous magnesium sulphate (MgSO4), disodium hydrogen citrate sesquihydrate (di$\mathrm{Na}$ ), trisodium citrate dihydrate (tri-Na) and Bondesil Primary-Secondary Amine (PSA) were provided by Sigma Aldrich (Saint Quentin Fallavier, France). Ultrapure water was obtained from a Milli-Q ${ }^{\circledR}$ water purification system connected to a LC-PAK cartridge to remove the remaining organic contaminants at trace levels (Millipore, Molsheim, France).

\subsubsection{Extraction procedure}

Extracts were prepared using QuEChERS as it is one of the most commonly applied procedures for pesticide residue extraction. $5 \mathrm{~g}$ of sample were weighed into a polypropylene tube. After addition of $10 \mathrm{~mL}$ of water and $10 \mathrm{~mL}$ of $\mathrm{MeCN}$, the sample was extracted by shaking by hand for at least $1 \mathrm{~min}$, and by vortex 1 more minute. Then a salt mixture ( $\mathrm{NaCl}, \mathrm{MgSO} 4$, di-Na, tri-Na) was added and the tube was shaken vigorously for a few seconds to prevent agglomeration. After shaking for 1 min the tubes were centrifuged at $1500 \mathrm{~g}$ to obtain a clarified MeCN extract. The supernatant was transferred into another tube (PSA) shaken for $1 \mathrm{~min}$ and centrifuged at 1500g for $4 \mathrm{~min}$. A $1 \mathrm{~mL}$ aliquot was taken and filtered through a nylon $0.45 \mu \mathrm{m}$ membrane filter. This final extract was injected in the LC-MS/MS system. The flowchart described in Figure 1 illustrates the steps of the extraction procedure in detail.

\subsubsection{LC-MS/MS analysis}

The analyses were performed using an Agilent 1200 Series Rapid Resolution Liquid Chromatograph (Agilent, Palo Alto, CA) equipped with a Cortecs column $(100 \mathrm{~mm} \times 2.1$ mm I.D., $2.7 \mu \mathrm{m}$ particle size, Waters; Milford, MA, USA) maintained at $30{ }^{\circ} \mathrm{C}$. The 
mobile phase consisted of $\mathrm{MeOH}$ and water acidified with $0.1 \%$ of formic acid. The gradient was applied at a flow rate of $0.4 \mathrm{~mL} / \mathrm{min}$ as follows: initial conditions of $5 \%$ MeCN increased linearly to $20 \%$ for 30 s, then increased linearly to $100 \%$ at min 6 , held at $100 \%$ for $2 \mathrm{~min}$ and returned to initial conditions for $5 \mathrm{~min}$. The inject volume was 5 $\mu \mathrm{L}$.

The MS-MS detection was performed using an Agilent 6410 Series Triple Quadruple (Agilent, Palo Alto, CA). The mass spectrometer was operated using electrospray ionization in the positive ion mode (ESI+). The capillary voltage was set to $4.0 \mathrm{kV}$. The source temperature was $350{ }^{\circ} \mathrm{C}$ and the desolvation temperature was $350{ }^{\circ} \mathrm{C}$. Nitrogen was used as the desolvation gas (flow $12 \mathrm{~L} / \mathrm{min}$ ) and collision gas at a pressure of $40 \mathrm{psi}$. Detection was performed in the multiple reaction monitoring (MRM) mode, this function automatically optimized the dwell times according to the number of simultaneously detected MRM transitions. The transition with the highest intensity was used as a quantifier and the second transition as a qualifier. Fragment voltage and collision energy were optimized for each pesticide, masses of precursor ions and product ions are summarized in Table 2.

\subsubsection{Validation of the analytical method}

The pesticide analytical methodology applied in this work was validated for every compound to ensure the reliability of the results in the quantification range considered. To this end, following the SANCO 12571/2013 guidance, the parameters: linearity, recovery, precision (repeatability or intraday precision "RSDr" and reproducibility or interday precision "RSDR”), limit of detection (LOD) and limit of quantification (LOQ) were calculated.

The linearity of the assay was investigated using matrix-matched standard calibration curves at the concentration range of 3-400 $\mu \mathrm{g} / \mathrm{kg}$ for amitraz, and 3-200 $\mu \mathrm{g} / \mathrm{kg}$ for the rest, in accordance with the MRL values for the target analytes established by the Regulation (EC) 396/2005 and the Regulation EU 37/2010 of the European Parliament and of the Council. Calibration curves were prepared in triplicate on three different days. For the determination of repeatability and reproducibility, for each compound five blank samples were spiked at a mass fraction level corresponding to the seven points of the calibration curve (3, 10, 20, 50, 100, 200 and $400 \mu \mathrm{g} / \mathrm{kg})$. Each level was processed and injected in triplicate. The same procedure was repeated on three additional days. 
Repeatability and reproducibility were determined by calculating the difference between the calculated and theoretical concentrations (RSD\%).

Accuracy was evaluated by recovery tests. The recovery was assessed by spiking blank samples at different mass fraction levels: 3, 10, 20, 50, 100, 200 and $400 \mu \mathrm{g} / \mathrm{kg}$, for three samples each. The recovery values were estimated by comparing both the measured and the theoretical mass fractions added.

The limit of quantitation (LOQ) of every compound was established considering the lowest concentration tested at which an unambiguous identification of the analyte was proved and at which an acceptable mean recovery with an acceptable relative standard deviation (RSD) was obtained.

\subsection{Risk Evaluation}

\subsubsection{Estimated daily intake (EDI)}

This parameter, expressed as $\mu \mathrm{gg}^{-1} \mathrm{~d}^{-1}$, is obtained as follows Eq 1:

$E D I=\frac{\mathrm{C} * \mathrm{Con}}{\mathrm{Bw}}$

Where $\left.\mathrm{C}(\mu \mathrm{g} \mathrm{kg})^{-1}\right)$ is the average concentration of a given pesticide in the collected honeys; $\mathrm{C}_{\mathrm{on}}\left(\mathrm{kg}\right.$ person $\left.{ }^{-1} \mathrm{~d}^{-1}\right)$ is the daily average consumption of honey in Spain; $\mathrm{Bw}$ $\left(\mathrm{kg} \mathrm{person}^{-1}\right)$ represents body weight. Based on the report by the Instituto Nacional de Estadística (Spanish National Institute of Statistics), the average honey consumption for adults is $0.7 \mathrm{~kg}$ per person per year, and the average body weight is $70 \mathrm{~kg}$ for adults (INE, 2012).

\subsubsection{Hazard quotient (HQ)}

This parameter is calculated for each pesticide by dividing the estimated daily intake (EDI) by the acceptable daily intake (ADI) $\left(\mu \mathrm{gg}^{-1} \mathrm{~d}^{-1}\right)$ for each pesticide (Table 1$)$, (USEPA, 2007b; Evans et al., 2015), Eq 2.

$H Q=\frac{\mathrm{EDI}}{\mathrm{ADI}}$

\subsubsection{Evaluation of hazard index (HI)}

The HI is a measurement of the potential risk of adverse health effects from a mixture of chemical constituents (Zheng et al., 2007; Evans et al., 2015).The Hazard Index (HI) is used in most MRA (Mixture risk Assessment) approaches. The HI due to daily average consumption of honey for a human being is obtained as the sum of the hazard quotient (HQ) calculated for each chemical, Eq 3: 
Conventionally, a HI less than 1 indicates that the total exposure does not exceed the level considered to be “acceptable", and people are unlikely to be exposed at a toxic level with possible consequences for health. On the contrary, if it exceeds one, there is a possibility of suffering adverse effects, (Evans et al., 2015; Yu et al., 2016).

\section{Results and Discussion}

\subsection{Matrix effect and in-house validation method}

Since co-extracted matrix constituents may cause ion suppressions or ion enhancement, therefore interfering with the quantitative result, the first step in the validation process was the evaluation of the matrix effect. To this end, for every studied compound, matrix effects were tested by comparing the slopes of the calibration curves obtained for the standard solutions prepared in solvent $(\mathrm{MeCN})$ with those prepared in blank matrix extracts (mix of 5 honeys). In general, medium or low matrix effects were observed, and therefore the calibration curves were constructed using the blank matrix extracts to avoid these effects. The levels of concentrations considered were: 3, 10, 20, 50, 100 and, 200 $\mu \mathrm{g} / \mathrm{kg}$. In addition, the level of $400 \mu \mathrm{g} / \mathrm{kg}$ was included in the calibration curve for amitraz; this is because this value corresponds to twice the MRL of this compound, as specified by SANCO guidelines.

Table 3 shows the data for the validation parameters. Linearity (expressed as $\mathrm{R}^{2}$ ), was in all cases higher than 0.9977 throughout the concentration range considered.

The recoveries of most of the studied compounds were in a range between 70 and 120\%, complying with the requirements of SANCO 12571/2013. On very few occasions the recoveries were less than 70\% (60\% and 66\% for coumaphos at levels $3 \mu \mathrm{g} / \mathrm{kg}$ and 10 $\mu \mathrm{g} / \mathrm{kg}$, respectively, and 66\% for 2,4-DMA at the level $50 \mu \mathrm{g} / \mathrm{kg}$ ). Amitraz was the most problematic compound because the recoveries ranged between 60 and $76 \%$ for 4 of the concentration levels used.

With respect to repeatability (RSDr) and reproducibility $\left(\mathrm{RSD}_{\mathrm{R}}\right)$, all the pesticides studied were in agreement with SANCO 12571/2013, since the values were less than $20 \%$. The only exception was coumaphos with $22.2 \%$ at the level of $10 \mu \mathrm{g} / \mathrm{kg}$ for repeatability, and coumaphos and amitraz, at the level of $20 \mu \mathrm{g} / \mathrm{kg}$, with $21.0 \%$ and $24.5 \%$ in the case of reproducibility. 
In the present study $3 \mu \mathrm{g} / \mathrm{kg}$ was considered to be the LOQ (limit of quantification) because it was the lowest validated point of the calibration curve for all the compounds, with acceptable trueness and precision results (SANCO 12571/2013).

Being a multi-residue analysis, in general, the values obtained for all the validation parameters can be considered acceptable. It is usual to reach a compromise in order to analyze all the compounds considered together (Kujawski \& Namiesnik, 2011).

\section{2. $\quad$ Analysis of the honey samples}

Few studies regarding the monitoring of pesticide residue levels in honey produced in Spain have been published previously (Blasco et al., 2003; Blasco et al., 2011); what is more, own-brands which contain mixtures from EU and non-EU countries honey have not been studied at all. Blasco et al. 2003 analyzed 42 pesticide residues (organochlorine, carbamate, and organophosphorus) in 50 samples of honey collected from local markets in Spain and Portugal during 2002; they found that of the 26 honey samples from Spain 16 (61\%) samples were contaminated with at least one pesticide and of the 24 Portuguese samples, pesticide residues were detected in 23 (95\%) samples.

Table 4 shows the concentration levels of pesticide residues obtained in the present work. All the pesticides studied were found in at least one of the samples investigated. In all cases the MRL established by the EU was satisfied. The pesticide which was present in all of the samples was amitraz (100\%). This fact is noteworthy because of the proved instability of this compound (Korta, et al., 2001; Farias et al., 2011) and taking into account the fact that the honey samples were relatively fresh according to the label. The next most frequently occurring compound was coumaphos (63.6\%), followed by pesticides such as acetamiprid (45.4\%) and simazine (40.9\%) used in agricultural practices. Amitraz and coumaphos are widely used in veterinary practices, in several European countries and the United States, due to their effectiveness against the varroa acarus. This results in the habitual presence of these compounds in honey (Lambert et al., 2013).

In the present work amitraz was found at an average value of $12.4 \mu \mathrm{g} / \mathrm{kg}(\mathrm{n}=22)$, followed by coumaphos $4 \mu \mathrm{g} / \mathrm{kg}(\mathrm{n}=14)$. Similar results were reported by Gómez-Pérez et al. in 2012, who detected $5.1 \mu \mathrm{g} / \mathrm{kg}$ of coumaphos in one Spanish sample. Barganska et al. (2013) quantified coumaphos in 6 out of 45 (13\%) Polish samples, where the concentration ranged from less than the limit of quantification $(4.95 \mu \mathrm{g} / \mathrm{kg})$ to $16.7 \mu \mathrm{g} / \mathrm{kg}$. 
A higher percentage of coumaphos in honey $(n=186)$ was found by the USDA $32.3 \%$ (USDA, 2015).

Lambert et al., 2013 studied the presence of 80 pesticides in honey, pollen and honey bees, obtained directly from apiaries in France. These authors found that the frequency of detection of these compounds was higher in the honey samples (28/141) than in pollen (23/128) or honey bee (20/141) samples. These authors observed that the acaricides, coumaphos (78.0\%) and amitraz (68.8\%) were the most frequently detected residues in honey.

In relation to chlorfenvinphos and tau-fluvalinate, in the present work the results showed that the first one was detected in $36.4 \%(n=8)$ of the samples with a mean concentration of $1.8 \mu \mathrm{g} / \mathrm{kg}$ and tau-fluvalinate $13.6 \%(\mathrm{n}=3)$ with an average value of $1.3 \mu \mathrm{g} / \mathrm{kg}$. Similar values were found (12.3\%) for tau-fluvalinate by the USDA pesticide data program (USDA, 2015).

Acetamiprid and simazine, which are related to agricultural practices, were found in the present study at mean values of 2.9 and $2.6 \mu \mathrm{g} / \mathrm{kg}$, respectively. Similar values were found by other authors who detected compounds that come from crop treatment which were also below the limits (Rissato et al., 2007; Barganska et al., 2013). In the present work chlorpyriphos was present in 10 samples (18.2\%) and imidacloprid in 9 (13.6\%) samples; with mean concentrations of $1.3 \mu \mathrm{g} / \mathrm{kg}$ and $2 \mu \mathrm{g} / \mathrm{kg}$, respectively. Comparing these results with published data, Rodriguez-López in 2014, detected chlorpyriphos in 50.1\% (31 out of 61 samples), however only two samples were higher than the limit of quantification (LOQ=5 $\mu \mathrm{g} / \mathrm{kg}$ ), with mean values of 6 and $21 \mu \mathrm{g} / \mathrm{kg}$, respectively. Panseri et al., 2014 detected chlorpyriphos in 33\% of the samples with a mean concentration of $5.6 \mu \mathrm{g} / \mathrm{kg}$. The results obtained by Rissato et al., in 2007, indicated a low level of contamination by pesticide residues, nevertheless, honey sampled in 2003 and 2004 had a concentration of 10 and $15 \mu \mathrm{g} / \mathrm{kg}$ of chlorpyrifos, respectively, while tau-fluvalinate was not detected.

In summary, $100 \%$ of honey samples contained at least one of the pesticides studied. Particularly, around $40 \%$ of the honey samples presented less than three pesticides and $18 \%$ only one pesticide. However, it is highlighted that in any case, the MRL was exceeded.

\subsection{Mix risk assessment}


Nowadays, there is concern that the chemical by chemical approach may not be sufficiently protective, especially when it is well known that humans are exposed to more than one chemical at a time (Evans, et al., 2015). The measure of the potential risk of adverse health to consumers due to the presence of a mixture of pesticides in honey is evaluated in the present work through the estimation of the hazard index (HI).

This is shown in Figure 2 for the mixture of pesticides in the 22 honey samples (ownbrands and well-known brands labelled as polyfloral), calculated as the sum of the hazard quotient (HQ) for each pesticide. The different colours in the bars refer to the contribution of each pesticide (HQ) to the HI value of each brand. On the $x$ axis, next to the code for each sample (from B1 to B22) appears the information about the countries of origin. It is well known that honey companies mix raw material from different sources to make up a production batch.

The HI values ranged between $5.510^{-6}$ in B9, and $1.810^{-3}$ in B8. This means that in the worst case, the HI value was 500 times lower than 1, the limit of acceptability. Few studies have been reported about the HI values for pesticides in other types of food. Among them, the study carried out by Yu et al. in 2016 should be highlighted. These authors conclude that the HI for adults for fresh vegetables $(n=214)$ due to 11 pesticides in Changchun (China) was 0.44. This value is less than half of the limit of acceptability; however it is much higher than that estimated for honey here. This is mainly due to the large quantitative difference in the consumption of both types of food. Therefore citizens are not exposed to a toxic level of pesticides via honey in sufficiently large quantities to cause possible health consequences (Evans et al., 2015; Yu et al., 2016).

In general, coumaphos followed by chlorfenvinphos had the highest contribution to the HI values, $71 \%$ and $15 \%$, respectively. It should be noted that both pesticides are classified as "highly hazardous" by the WHO and "highly toxic" by the WHO (2010). Third was amitraz HQ (8\%), which despite being classified as "moderately hazardous" by OMS, in the present paper had the highest exposure $(100 \%$ of the honey brands sampled). Simazine represented $2 \%$, followed by chorpyrifos-methyl, chlorpyrifos, cyproconazole and tau-fluvalinate, all of them with $1 \%$. Therefore, $94 \%$ are due to veterinary practices.

Considering the country of origin of honey, it is observed that the presence of pesticide residues does not conform to a geographic pattern. In this regard, it is noted that a country can be associated with both high HI values and very low HI values. Therefore, the 
presence of pesticides may be associated with specific beekeeping practices carried out against the varroa acarus. This can vary from year to year because the propagation of this parasite is greatly influenced by weather conditions (Garrido-Bailón et al., 2012).

\section{Conclusions}

The analytical procedure developed to determine eleven pesticide residues in honey permits a level of quantification of $3 \mu \mathrm{g} / \mathrm{kg}$ and detection of $1 \mu \mathrm{g} / \mathrm{kg}$. All the pesticides studied were found in at least one of the retail polyfloral brands analysed. The highest percentages correspond to those that come from veterinary treatments, especially amitraz and coumaphos, followed by pesticides such as acetamiprid and simazine used in agricultural practices. The samples contained pesticide residues at different concentration levels, however, the MRL in honey for each of the 11 pesticides was not exceeded, in any of the cases.

In relation to the individual hazard quotient, coumaphos followed by chlorfenvinphos and amitraz had the highest contribution to the HI values, which means that, veterinary treatments are the main source of pesticides in honey. However, the hazard index (HI) for adults was always less than 0.002, infinitesimal compared to the value of 1 recognized as the level considered to be "acceptable". Therefore, although it is known that some of the chemical compounds evaluated act toxicologically similarly and with the same mechanism of action (neurotoxic effect), in the worst case-scenario the daily intake of pesticides through brands labelled as polyfloral honey is not an important pathway for the dietary exposure of citizens and consequently does not entail a significant health risk. However, we should not be satisfied with this, but strive to attain the ALARA principle (As Low As Reasonably Achievable), by which residues have to be eliminated or minimized as much as possible. This requires an effort by the primary sector: farmers and beekeepers, as their practices have the greatest influence on this problem.

In conclusion, this work not only evidences that the safety of consumers seems to be generally under control in terms of cumulative pesticide intake through retail honey consumption, but for the first time gives real data about the exposure to pesticide residues as a consequence of this kind of food. This information, together with that provided about the exposure to pesticides considering other food products (such as vegetables and fruit) will be useful to better understand the global exposition of pesticides to consumers through diet. 


\section{Acknowledgment}

This study forms part of a project funded by the Ministerio de Educación y Ciencia of Spain (Programa Estatal de Investigación Desarrollo e Innovación Orientada a los retos de la sociedad; Project number AGL2013-48646-R), for which the authors are grateful.

\section{References}

Barganska, Z., Slebioda, M., \& Namiesnik, J. (2013). Pesticide residues levels in honey from apiaries located of Northern Poland. Food Control, 31, 196-201.

Blasco, C., Fernandez, M.; Pena, A., Lino C., Silveira, I., Font, G. \& Pico, Y. (2003). Assessment of Pesticide Residues in Honey Samples from Portugal and Spain. Journal of Agricultural and Food Chemistry, 51, 8132-8138.

Blasco, C., Vázquez-Roig, P., Onghena, M., Masia, A., \& Picó, Y. (2011). Analysis of insecticides in honey by liquid chromatography-ion trap-mass spectrometry: Comparison of different extraction procedures. Journal of Chromatography A, 1218, 4892-4901.

Boobis, A.R., Ossendorp, B.C., Banasiak, U., Hamey, P.Y., Sebestyen, I., \& Moretto, A. (2008). Cumulative risk assessment of pesticide residues in food. Toxicology letters. 180 (2), 137-150.

Calatayud-Vernich, P., Calatayud, F., Simó, E., Morales Suarez-Varela, M., \& Picó, Y. (2016). Influence of pesticide use in fruit orchards during blooming on honeybee mortality in 4 experimental apiaries. Science of The Total Environment, 41, 15 January, 33-41.

Corta, E., Bakkali, A., Berrueta, L.A., Gallo, B., Vicente, F. (1999). Kinetics and mechanism of amitraz hydrolysis in aqueous media by HPLC and GC-MS. Talanta 48 189-199.

COT (UK Committee on Toxicity of Chemicals in Food, Consumer Products and the Environment). (2002). Risk Assessment of Mixtures of Pesticides and Similar Substances. Available online: http://cot.food.gov.uk/pdfs/reportindexed.pdf

CVUA (2007). Chemisches und Veterinäruntersuchungsamt Stuttgart/Germany. Toxikologische Bewertung von Mehrfachrückständen in Obst und Gemüse. Report EFSA (European Food Safety Authority). (2013). International frameworks dealing with human risk assessment of combined exposure to multiple chemicals. EFSA Journal 2013;11(7):3313. Available at: http://www.efsa.europa.eu/sites/ default/files/scientific_output/files/main_documents/3313.pdf 
Evans, RM., Scholze, M., \& Kortenkamp A. (2015). Examining the feasibility of mixture risk assessment: A case study using a tiered approach with data of 67 pesticides from the Joint FAO/WHO Meeting on Pesticide Residues (JMPR). Food and Chemical Toxicology. 84, 260-269.

Farias, T.M.B., Santana, J.C.C. \& Calarge, F.A. (2011). Study of Stability of $\mathrm{C}_{19} \mathrm{H}_{23} \mathrm{~N}_{3}$ (amitraz) through Analysis FT-IR Spectroscopy. 3rd International Workshop |Advances in Cleaner Production, 1-7.

Gallagher, S.S., Rice, G.E., Scarano, L.J., Teuschler, L.K., Bollweg, G. \& Martin, L. (2015). Cumulative risk assessment lessons learned: A review of case studies and issue papers. Chemosphere, 120, 697-705.

García-Chao, M., Agruña, M.J., Flores Calvete, G., Sakkas, V., Llompart, M. \& Dagnac, T. (2010). Validation of an off line solid phase extraction liquid chromatographytandem mass spectrometry method for the determination of systemic insecticide residues in honey and pollen samples collected in apiaries from NW Spain. Analytica Chimica Acta. 672, 107-113.

Garrido-Bailón, E., Botías C., Martin-Hernandez, R., Meartinez-Salvador, A., Meana A. \& Higes M. (2012). Prevalencia de los principales Agentes Patógenos de Apis mellifera iberiensis en la cabaña apícola Española. Anales Real Academia de Ciencias Veterinarias de Andalucía Oriental. 25 (1), 109-130.

Gómez-Pérez, M.L., Plaza-Bolaños, P., Romero-González, R. Martínez-Vidal, J.L. \& Garrido-Frenich A. (2012). Comprehensive qualitative and quantitative determination of pesticides and veterinary drugs in honey using liquid chromatography-Orbitrap high resolution mass spectrometry. Journal of Chromatography A, 1248, 130-138

Hou, X., Han, M. Dai, X., Yang, X. \& Yi, S. (2013). A multi-residue method for the determination of 124 pesticides in rice by modified QuEChERS extraction and gas chromatography-tandem mass spectrometry. Food Chemistry, 138, 1198-1205.

INE (Instituto Nacional de Estadística). (2012). Data of consumption. Available at: http://www.ine.es/

Juan-Borrás, M., Periche, A., Domenech, E., \& Escriche, I. (2015). Routine quality control in honey packaging companies as a key to guarantee consumer safety. The case of the presence of sulfonamides analyzed with LC-MS-MS. Food Control, 50, 243249.

Judge, S.J., Savy, C.Y. , Campbell, M., Dodds, R., Gomes, L.K., Laws, G., Watson, A., Blain, P.G., Morris, C.M., \& Gartside, S.E. Mechanism for the acute effects of 
organophosphate pesticides on the adult 5-HT system. (2016). Chemico-Biological Interactions, 245, 82-89.

Kasiotis, K.M., Anagnostopoulos, C., Anastasiadou, P., \& Machera, K., (2014). Pesticide residues in honeybees, honey and bee pollen by LC-MS/MS screening: reported death incidents in honeybees. Science of the Total Environment 63, 485-486.

Korta, E., Bakkali, A., Berrueta, L.A., Gallo, B.F., Kilchenmann, V.V. \& Bogdanov S. (2001). Study of Acaricide Stability in Honey. Characterization of Amitraz. Degradation Products in Honey and Beeswax. Journal Agriculture and Food Chemistry, 49, 5835-5842.

Kortenkamp, A., Backhaus, T., \& Faust, M. (2009). State of the Art on Mixture Toxicity. Report. Available at: http://ec.europa.eu/environment/chemicals/pdf/report_Mixture\%20toxicity.pdf.

Kujawski, M.W., \& Namiesnik, J. (2011). Levels of 13 multi-class pesticide residues in Polish honeys determined by LC-ESI-MS/MS. Food Control, 22, 914-919.

Lambert, O., Piroux, M., Puyo, S., Thorin, C., L’Hostis, M., Wiest, L., Bulete, A., Delbac, F. \& Pouliquen, H. (2013) Widespread Occurrence of Chemical Residues in Beehive Matrices from Apiaries Located in Different Landscapes of Western France. Available at: http://journals.plos.org/plosone/article?id=10.1371/journal.pone.0067007.

Li, Y., Kelley, R.A., Anderson, T. D. \& Lydy, M.J. (2015). Development and comparison of two multi-residue methods for the analysis of select pesticides in honey bees, pollen, and wax by gas chromatography-quadrupole mass spectrometry. Talanta. 140, 81-87.

OECD (2011). WHO OECD ILSI/HESI International Workshop on Risk Assessment of Combined Exposures to Multiple Chemicals. Paris, France, OECD Environment Directorate. OECD Environment, Health and Safety Publications. Series on Testing and Assessment.

Panseri, S., Catalano, A., Giorgi, A., Arioli, F., Procopio, A., Britti, D., \& Chiesa L.M. (2014). Occurrence of pesticide residues in Italian honey from different areasin relation to its potential contamination sources. Food Control, 38, 150-156.

Quijano, L., Vicent Yusá, V., Font, G., Pardo, O. (2016). Chronic cumulative risk assessment of the exposure to organophosphorus, carbamate and pyrethroid and pyrethrin pesticides through fruit and vegetables consumption in the region of Valencia (Spain). Food and Chemical Toxicology, 89, 39-46. 
Regulation (EU) No 37/2010 of 22 December 2009 on pharmacologically active substances and their classification regarding maximum residue limits in foodstuffs of animal origin. Available at: http://ec.europa.eu/health/files/eudralex/vol5/reg_2010_37/reg_2010_37_en.pdf.

Regulation (EC) $N^{o} 396 / 2005$ of the European Parliament and of the Council of 23 February 2005 on maximum residue levels of pesticides in or on food and feed of plant and animal origin and amending Council Directive 91/414/EEC, European Community, Brussels, 16-3-2005. Available at: http://eurlex.europa.eu/LexUriServ/LexUriServ.do?uri=OJ:L:2005:070:0001:0016:en:PDF

Rissato, S. R., Galhiane, M. S., de Almeida, M. V., Gerenutti, M., \& Apon, B. M. (2007). Multiresidue determination of pesticides in honey samples by gas chromatographymass spectrometry and application in environmental contamination. Food Chemistry. 101(4), 1719-1726.

Rodriguez-López, D., Ahumada, D. A., Díaz, A. C., \& Guerrero, J. A. (2014). Evaluation of pesticide residues in honey from different geographic regions of Colombia. Food Control, 37, 33-40.

SANCO 12571/2013. (2013). Method Validation and Quality Control Procedures for Pesticide Residue Analysis in Food and Feed. Available at: http://ec.europa.eu/food/plant/pesticides/guidance_documents/docs/qualcontrol_en.p df.

Tanner, G., \& Czerwenka, C. (2011). LC-MS/MS analysis of neonicotinoid insecticides in honey: methodology and residue findings in Austrian honeys. Journal of Agricultural and Food Chemistry, 59 (23), 12271-12277.

Tokmana, N., Solera, C., Farré, M., Picó, Y., Barceló, D. (2009). Determination of amitraz and its transformation products in pears by ethyl acetate extraction and liquid chromatography-tandem mass spectrometry. Journal of Chromatography A, 1216, 3138-3146.

Totti, S., M. Fernández, S. Ghini, Y. Picó, F. Fini, J. Mañes \& S. Girotti. (2006). Application of matrix solid phase dispersion to the determination of imidacloprid, carbaryl, aldicarb, and their main metabolites in honey bees by liquid chromatographymass spectrometry detection. Talanta 69: 724-729.

USEPA (2002). Guidance on Cumulative Risk Assessment of Pesticide Chemicals That Have a Common Mechanism of Toxicity. 14 January 2001. Office of Pesticide Programs, Office of Prevention, Pesticides, and Toxic Substances. Washington, DC 
USEPA (2006). Organophosphorus Cumulative Risk Assessment. Retrieved from. www.epa.gov/pesticides/cumulative (accessed November 2015).

USEPA (2007a). Revised N-methyl Carbamate Cumulative Risk Assessment. Retrieved from. www.epa.gov/pesticides/cumulative (accessed November 2015).

USEPA (2007b). Integrated risk information system-database (Philadelphia PA; Washington, DC).

USEPA (2011). Pyrethrins/pyrethroid Cumulative Risk Assessment. Retrieved from. www.epa.gov/pesticides/cumulative (accessed November 2015).

USDA (2015). Pesticides data program. Available at: http://www.ams.usda.gov/datasets/pdp.

Van Engelsdorp, D., Evans, J., Saegerman C., Mullin C., Haubruge E, Nguyen B.K., Frazier M., Frazier, J., Cox-Foster D., Chen Y., Underwood R., Tarpy D.R., \& Pettis J.S. (2009). Colony Collapse Disorder: A Descriptive Study. Available at: http://journals.plos.org/plosone/article?id=10.1371/journal.pone.0006481.

VKM (2008). Norwegian Scientific Committee for Food Safety. Combined toxic effects of multiple chemical exposures. Report.105 pp. Available online: http://vkm.no/dav/15ec300082.pdf.

WHO (World Health Organization) (2010). The WHO recommended classification of pesticides by hazard. Available at: http://www.who.int/ipcs/publications/pesticides_hazard/en/

WHO (World Health Organization) (2012). Inventory of evaluations performed by the Joint Meeting on Pesticide Residues (JMPR). Available at: http://apps.who.int/pesticide-residues-jmpr-database/Home/Search

Xu, J.Z., Miao, J.J., Lin, H., Ding, T.; Zhao, Z.Y.; Wu1, B.; Shen, C.Y. \& Jiang, Y. (2009). Determination of amitraz and 2,4-dimethylaniline residues in honey by using LC with UV detection and MS/MS, Journal of Separation Science, 32, 4020-4024.

Yu, R., Liu, Q., Liu, J., Wang, Q., \& Wang, Y. (2016). Concentrations of organophosphorus pesticides in fresh vegetables and related human health risk assessment in Changchun, Northeast China. Food Control, 60, 353-360.

Zheng, N., Wang, Q., Zhang, X., Zheng, D., Zhang, Z., \& Zhang, S. (2007). Population health risk due to dietary intake of heavy metals in the industrial area of Huludao city, China. Science of the Total Environment, 387(1), 96-104.

\section{Figure Caption}




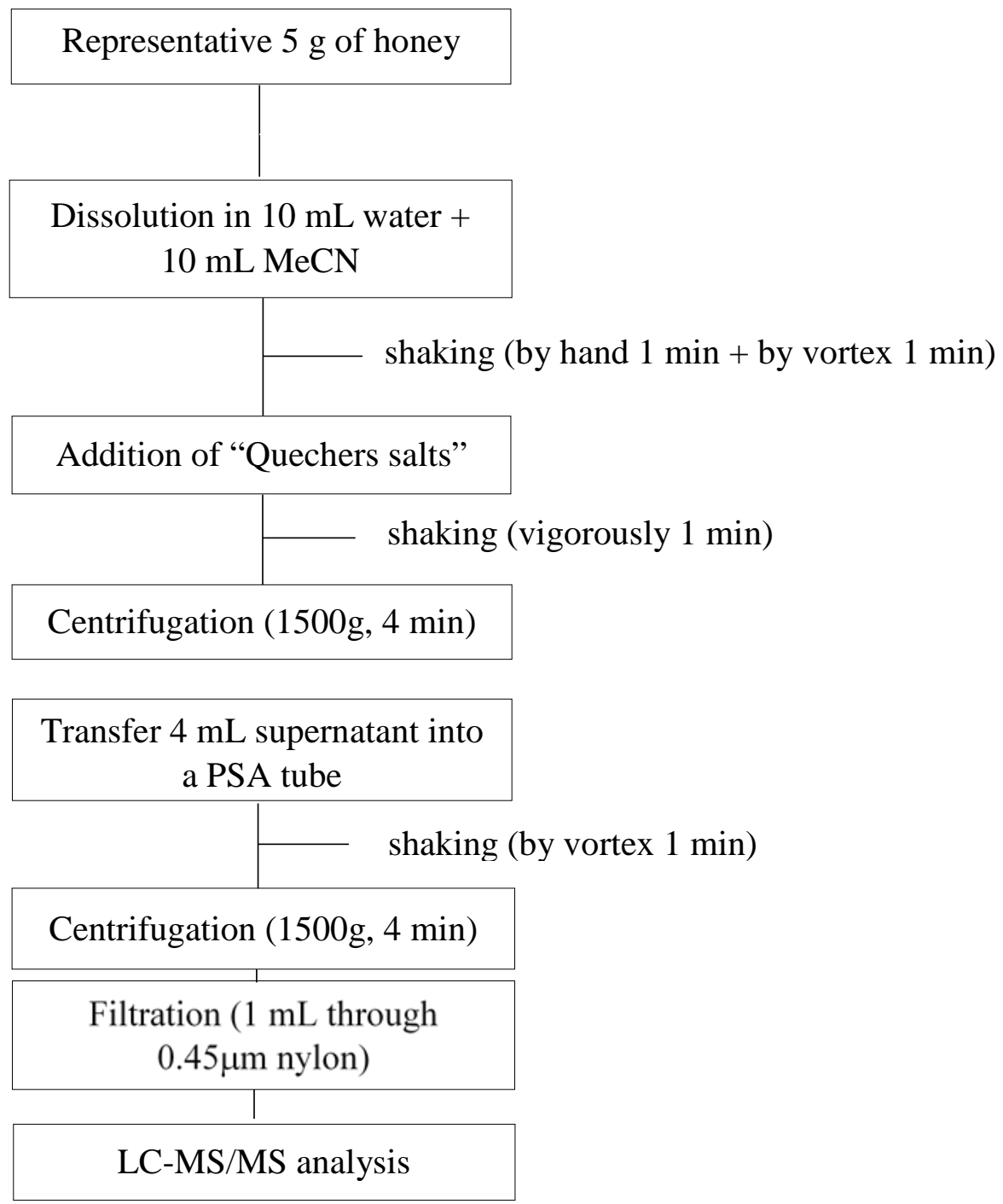

Figure 1. Flowchart of the steps applied in the extraction procedure. 


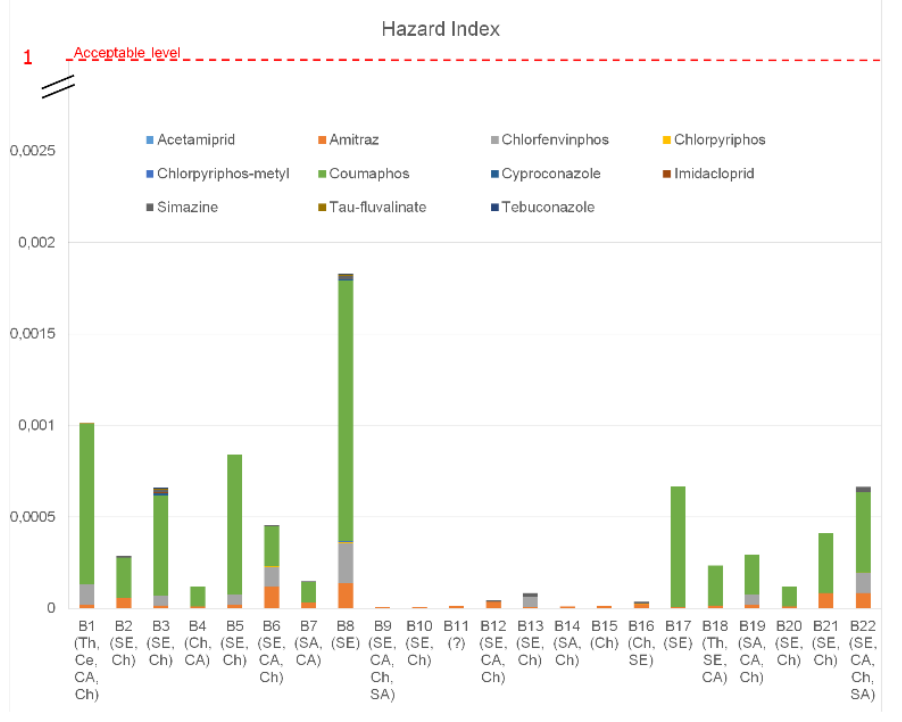

Figure 2. Hazard Index of the mixture of 11 pesticides in the 22 samples (own-brands and well-known brands labelled as polyfloral). Different colours in the bars refer to the contribution of each pesticide (HQ) in the HI of each brand. Country origin: SE (Southern Europe); Ch (China); CA (Central America); SA (South America); Th (Thailand); Ce (Chile); ? (unknown origin).

Table 1. Pesticides studied in the present work.

\begin{tabular}{llllll}
\hline $\begin{array}{l}\text { Common } \\
\text { name }\end{array}$ & $\begin{array}{l}\text { Biocide } \\
\text { action }\end{array}$ & $\begin{array}{l}\text { Pesticide } \\
\text { family }\end{array}$ & MRL $^{\mathbf{a}}$ & ADI $^{\mathbf{b}}$ & WHO $^{\mathbf{c}}$ \\
\hline Veterinary practices & & & & & \\
Amitraz & Acaricide & Formamidine & $200^{(1)}$ & 10 & III \\
$\begin{array}{l}\text { Chlorfenvinphos } \\
\text { Coumaphos }\end{array}$ & $\begin{array}{l}\text { Acaricide } \\
\text { Acaricide }\end{array}$ & $\begin{array}{l}\text { Organophosphorus } \\
\text { Organophosphorus }\end{array}$ & 10 & 0.5 & IB \\
Tau-fluvalinate & Acaricide & Pyrethroid & 50 & 5 & U \\
\hline Agricultural practices & & & & & \\
Acetamiprid & Insecticide & Neonicotinoid & 50 & 70 & II \\
Chlorpyrifos & Insecticide & Organophosphorus & 10 & 10 & II \\
Chlorpyriphos-methyl & Insecticide & Organophosphorus & 10 & 10 & III \\
Cyproconazole & Fungicide & Azole & 50 & 10 & III \\
Imidacloprid & Insecticide & Neonicotinoid & 50 & 60 & II \\
Simazine & Herbicide & Triazine & 10 & 5 & U
\end{tabular}




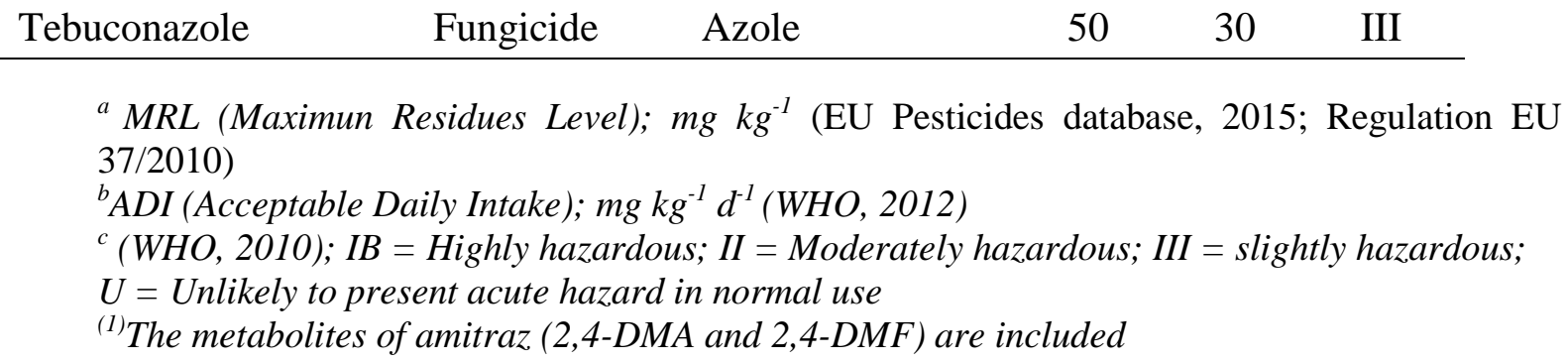

Table 2. Settings for the ion transitions of the thirteen selected pesticides studied in MRM mode

\begin{tabular}{|c|c|c|c|c|c|}
\hline Compound & $\begin{array}{l}\text { Precursor } \\
\text { Ion }\end{array}$ & $\begin{array}{c}\text { Product } \\
\text { Ion } 1 \\
(\mathrm{~m} / \mathrm{z}) \\
\end{array}$ & $\begin{array}{c}\text { Product } \\
\text { Ion } 2 \\
(\mathrm{~m} / \mathrm{z}) \\
\end{array}$ & $\begin{array}{c}\text { Collision } \\
\text { energy } \\
(\mathrm{V})\end{array}$ & $\begin{array}{c}\text { Retention } \\
\text { Time } \\
(\mathrm{min})\end{array}$ \\
\hline Amitraz & 294.2 & 163.0 & 122.0 & $10 / 35$ & 10.20 \\
\hline 2,4-DMA & 122.1 & 77.0 & 107.0 & 30 & 6.20 \\
\hline $2,4-\mathrm{DMF}$ & 150.0 & 107.0 & 123.2 & $18 / 13$ & 8.40 \\
\hline Chlorfenvinphos & 359.0 & 154.7 & 126.8 & $10 / 15$ & 9.49 \\
\hline Coumaphos & 363.0 & 306.6 & 226.4 & $10 / 40$ & 9.52 \\
\hline Tau-fluvalinate & 503.1 & 180.9 & 207.7 & $37 / 5$ & 10.30 \\
\hline Acetamiprid & 223.0 & 126.0 & 56.0 & 15 & 7.72 \\
\hline Chlorpiryphos & 351.6 & 200.0 & 97.0 & 15 & 9.99 \\
\hline Chlorpiryphos-methyl & 324.0 & 125.0 & 292.0 & 15 & 9.66 \\
\hline Cyproconazole & 292.1 & 69.9 & 124.7 & $17 / 37$ & 9.28 \\
\hline Imidacloprid & 256.1 & 209.3 & 175.4 & $15 / 20$ & 7.30 \\
\hline Simazine & 202.1 & 132.0 & 123.9 & 20 & 8.63 \\
\hline Tebuconazole & 308.2 & 69.9 & 124.7 & $21 / 5$ & 9.48 \\
\hline
\end{tabular}


Table 3. Validation parameters for the chemical compounds studied.

\begin{tabular}{|c|c|c|c|c|c|c|c|c|c|c|c|c|c|c|c|}
\hline \multirow[t]{2}{*}{ Analyte } & \multirow[b]{2}{*}{$\mathbf{R}^{2}$} & \multicolumn{2}{|c|}{$3 \mu \mathrm{g} / \mathrm{kg}$} & \multicolumn{2}{|c|}{$10 \mu \mathrm{g} / \mathrm{kg}$} & \multicolumn{3}{|c|}{$20 \mu \mathrm{g} / \mathrm{kg}$} & \multicolumn{2}{|c|}{$50 \mu \mathrm{g} / \mathrm{kg}$} & \multicolumn{2}{|l|}{$100 \mu \mathrm{g} / \mathrm{kg}$} & \multicolumn{2}{|l|}{$200 \mu \mathrm{g} / \mathrm{kg}$} & \multirow{2}{*}{$\frac{400 \mu \mathrm{g} / \mathrm{kg}}{\text { Recovery RSDr }}$} \\
\hline & & Recovery & RSDr & Recovery & RSDr & Recovery & RSDr & $\mathbf{R S D}_{\mathbf{R}}$ & Recovery & RSDr & Recovery & RSDr & Recovery & RSDr & \\
\hline Amitraz & 0.9988 & $60(10)$ & 12.8 & $66(6)$ & 16.8 & 67 (13) & 12.6 & 24.5 & $76(5)$ & 15.4 & 70 (8) & 10.7 & $63(5)$ & 10.0 & 69 (8) 8.4 \\
\hline 2,4-DMA & 0.9990 & $76(3)$ & 5.0 & $70(4)$ & 5.1 & $74(3)$ & 4.1 & 7.2 & $66(4)$ & 5.4 & $70(2)$ & 2.2 & $79(1)$ & 0.8 & \\
\hline 2,4-DMF & 0.9996 & $98(3)$ & 3.5 & $101(7)$ & 4.8 & $92(4)$ & 4.8 & 0.9 & $86(2)$ & 2.4 & $86(2)$ & 2.5 & $91(4)$ & 4.9 & \\
\hline Chlorfenvinphos & 0.9989 & $93(4)$ & 9.0 & $96(13)$ & 13.9 & $97(6)$ & 5.8 & 7.6 & $89(6)$ & 7.3 & $98(4)$ & 4.2 & $102(2)$ & 1.7 & \\
\hline Coumaphos & 0.9993 & $60(14)$ & 20.0 & $66(34)$ & 22.2 & $90(10)$ & 11.2 & 21.0 & $94(10)$ & 10.8 & $95(8)$ & 8.0 & $101(2)$ & 1.8 & \\
\hline Tau-fluvalinate & 0.9977 & $80(5)$ & 8.2 & 87 (6) & 7.4 & $84(3)$ & 4.0 & 8.9 & $82(2)$ & 2.8 & $81(2)$ & 2.0 & 87 (3) & 3.4 & \\
\hline Acetamiprid & 0.9997 & $98(6)$ & 4.6 & $101(7)$ & 7.2 & $97(2)$ & 2.6 & 3.8 & $91(3)$ & 3.1 & $95(2)$ & 2.1 & $99(1)$ & 0.8 & \\
\hline Chlorpiryphos & 0.9990 & $85(2)$ & 10.2 & 89 (17) & 18.5 & $86(7)$ & 6.5 & 17.1 & $78(6)$ & 8.1 & $86(3)$ & 3.4 & $92(3)$ & 2.9 & \\
\hline $\begin{array}{l}\text { Chlorpiryphos- } \\
\text { methyl }\end{array}$ & 0.9988 & $82(12)$ & 5.0 & $80(14)$ & 5.2 & $87(2)$ & 2.5 & 16.8 & $79(4)$ & 5.3 & $87(2)$ & 2.7 & $91(2)$ & 2.0 & \\
\hline Cyproconazole & 0.9998 & $90(4)$ & 6.6 & $91(7)$ & 7.4 & $93(5)$ & 4.9 & 5.1 & $85(4)$ & 4.5 & $90(2)$ & 2.1 & $95(1)$ & 0.9 & \\
\hline Imidacloprid & 0.9998 & $102(4)$ & 5.2 & $113(9)$ & 8.1 & 102 (3) & 2.8 & 5.0 & $98(3)$ & 3.6 & $96(2)$ & 1.9 & $98(1)$ & 0.7 & \\
\hline Simazine & 0.9997 & $95(2)$ & 6.0 & $101(7)$ & 7.0 & $92(3)$ & 3.0 & 5.6 & $89(3)$ & 3.1 & $94(1)$ & 1.1 & $96(1)$ & 0.9 & \\
\hline Tebuconazole, & 0.9996 & $101(8)$ & 9.0 & $104(2)$ & 11.7 & $100(4)$ & 4.4 & 4.3 & $96(5)$ & 4.7 & $97(3)$ & 2.7 & $102(2)$ & 1.7 & \\
\hline
\end{tabular}


Table 4. Average concentration $\left(\mu \mathrm{g} / \mathrm{kg}^{\mathrm{a}}\right)$ of pesticides present in the 22 own-brand and well-known brand samples of honey $(n=3)$.

\begin{tabular}{|c|c|c|c|c|c|c|c|c|c|c|c|}
\hline 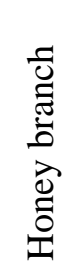 & 苞 & 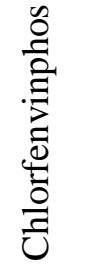 & 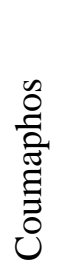 & 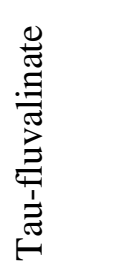 & 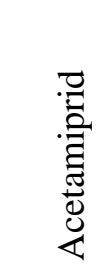 & 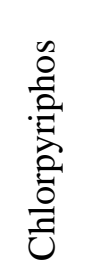 & 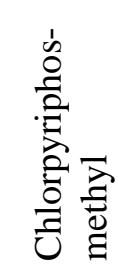 & 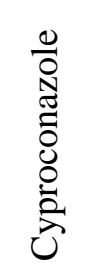 & 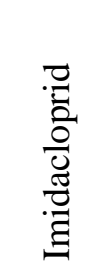 & $\begin{array}{l}\stackrel{\mathscr{N}}{\mathbb{N}} \\
\text { 节 }\end{array}$ & 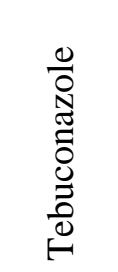 \\
\hline B1 & 8 & 2 & 8 & 1 & n.d. & n.d. & n.d. & n.d. & n.d. & n.d. & n.d. \\
\hline B2 & 21 & n.d. & 2 & n.d. & 3 & n.d. & n.d. & n.d. & n.d & 2 & n.d. \\
\hline B3 & 5 & 1 & 5 & 1 & 3 & n.d. & n.d. & 5 & 3 & 3 & 4 \\
\hline B4 & 3 & n.d. & 1 & n.d. & 6 & n.d. & n.d. & n.d. & n.d. & n.d. & n.d. \\
\hline B5 & 7 & 1 & 7 & n.d. & 2 & n.d. & n.d. & n.d. & n.d. & n.d. & n.d. \\
\hline B6 & 43 & 2 & 2 & n.d. & n.d. & 1 & n.d. & n.d. & n.d. & 1 & n.d. \\
\hline B7 & 12 & n.d. & 1 & n.d. & n.d. & n.d. & n.d. & n.d. & n.d. & 1 & n.d. \\
\hline B8 & 50 & 4 & 13 & 2 & 2 & 2 & 2 & 2 & 2 & 3 & 2 \\
\hline B9 & 2 & n.d. & n.d. & n.d. & n.d. & n.d. & n.d. & n.d. & n.d. & n.d. & n.d. \\
\hline B10 & 2 & n.d. & n.d. & n.d. & 4 & n.d. & n.d. & n.d. & n.d. & n.d. & n.d. \\
\hline B11 & 5 & n.d. & n.d. & n.d. & n.d. & n.d. & n.d. & n.d. & n.d. & n.d. & n.d. \\
\hline B12 & 13 & n.d. & n.d. & n.d. & n.d. & n.d. & n.d. & n.d. & n.d. & 2 & n.d. \\
\hline B13 & 3 & 1 & n.d. & n.d. & 2 & n.d. & n.d. & n.d. & n.d. & 4 & n.d. \\
\hline B14 & 4 & n.d. & n.d. & n.d. & n.d. & n.d. & n.d. & n.d. & n.d. & n.d. & n.d. \\
\hline B15 & 5 & n.d. & n.d. & n.d. & n.d. & n.d. & n.d. & n.d. & n.d. & n.d. & n.d. \\
\hline B16 & 8 & n.d. & n.d. & n.d. & 3 & 1 & n.d. & n.d. & n.d. & 2 & n.d. \\
\hline B17 & 3 & n.d. & 6 & n.d. & n.d. & n.d. & n.d. & n.d. & n.d. & n.d. & n.d. \\
\hline B18 & 6 & n.d. & 2 & n.d. & n.d. & n.d. & n.d. & n.d. & n.d. & n.d. & n.d. \\
\hline B19 & 7 & 1 & 2 & n.d. & 1 & n.d. & n.d. & n.d. & 1 & n.d. & n.d. \\
\hline B20 & 4 & n.d. & 1 & n.d. & n.d. & n.d. & n.d. & n.d. & n.d. & n.d. & n.d. \\
\hline B21 & 30 & n.d. & 3 & n.d. & 3 & n.d. & n.d. & n.d. & n.d. & n.d. & n.d. \\
\hline B22 & 31 & 2 & 4 & n.d. & n.d. & 1 & n.d. & n.d. & n.d. & 5 & n.d. \\
\hline $\mathrm{N}$ & $\begin{array}{c}22 \\
(100 \%\end{array}$ & $\begin{array}{c}8 \\
6.4 \%\end{array}$ & $\begin{array}{c}14 \\
3.6 \%\end{array}$ & $\begin{array}{c}3 \\
3.6 \%)\end{array}$ & $\begin{array}{c}10 \\
(45.4 \%\end{array}$ & $\begin{array}{c}4 \\
8.1 \%\end{array}$ & $\begin{array}{c}1 \\
(4.5 \%)\end{array}$ & $\begin{array}{c}2 \\
(9.1 \%)\end{array}$ & $\begin{array}{c}3 \\
(13.6 \%\end{array}$ & $\begin{array}{c}9 \\
(40.90\end{array}$ & $\begin{array}{c}2 \\
(9.1 \%)\end{array}$ \\
\hline
\end{tabular}

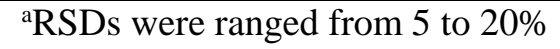

n.d.= non detected

$\mathrm{N}=$ Number of samples with presence of pesticides

*= amitraz and its metabolites
} 